\title{
PENDAMPINGAN GURU - GURU DALAM PEMBUATAN RAPORT KURIKULUM 2013 DI MI MIFTAHUL HIDAYAH GUNUNGPATI SEMARANG
}

\author{
Yani Parti Astuti*1, Egia Rosi Subhiyakto ${ }^{2}$, Prajanto Wahyu Adi $^{3}$ \\ ${ }^{1,2}$ Universitas Dian Nuswantoro; jl. Imam Bonjol 207 Semarang, (+6224) 3517261 \\ ${ }^{3}$ Jurusan Teknik Informatika, Fasilkom Udinus, Semarang \\ e-mail: *1yanipartiastuti@dsn.dinus.ac.id, 2egia.rosi.subhiyakto@dsn.dinus.ac.id, \\ prajanto@dsn.dinus.ac.id
}

\begin{abstract}
Abstrak
Sistem Pendidikan Indonesia sering berubah - ubah berdasarkan perkembangan teknologi di Indonesia. Hal ini dibuktikan dengan penerapan kurikulum 2013 pada setiap sekolah baik SD/MI sampai jenjang SMA/SMK. Pada kurikulum 2013 terjadi perubahan baik dalam materi maupun administrasi. Di bidang materi setiap guru bisa mempersiapkan dengan baik dan terpercaya. Namun untuk segi administrasi diperlukan waktu untuk mempelajarinya khususnya dalam pembuatan raport. Untuk itu, maka dinas pendidikan memberikan sistem yang dipelajari oleh setiap guru yang sudah menggunakan kurikulum 2013. Sehingga perlu diadakan pendampingan agar dalam pembuatan raport kurikulum 2013 bisa direalisasikan. Sebagai hasil dari pendampingan ini, maka setiap guru bisa membuat raport kurikulum 2013 dengan baik dan benar.
\end{abstract}

Kata kunci-Kurikulum, Administrasi, raport

\begin{abstract}
Indonesia's education system often changes using technology developments in Indonesia. This is evidenced by applying the 2013 curriculum at every school both elementary / MI to high school / vocational level. In the 2013 curriculum there were changes in both material and administration. In the material field each teacher can be prepared well and reliably. But for the administrative aspect it takes time to learn it specifically in making report cards. For this reason, the education office provides a system that is learned by every teacher who has used the 2013 curriculum. Mentoring is needed so that the preparation of the 2013 curriculum report can be realized. As a result of this assistance, each teacher can make a 2013 curriculum report properly.
\end{abstract}

Keywords — curriculum, administrative, report

\section{PENDAHULUAN}

Menurut Undang - Undang Nomor 20 tahun 2003 tentang Sistem Pendidikan Nasional menyebutkan bahwa kurikulum merupakan seperangkat rencana dan pengaturan mengenai tujuan, isi dan bahan pembelajaran dan cara yang digunakan untuk pedoman pembelajaran untuk mencapai tujuan tertentu [1]. Untuk itu kurikulum harus selalu mengikuti perkembangan teknologi pada periode atau masa tertentu. Seperti halnya pada masa sekarang yang mulai diberlakukan kurikulum baru yaitu kurikulum 2013 yang sudah diatur dalam Peraturan Menteri Pendidikan dan Kebudayaan Nomor 67 Tahun 2013. Pada Peraturan Menteri tersebut membahas tentang Kerangka Dasar dan Struktur Kurikulum sekolah Dasar / Madrasah Ibtidaiyah. 
Kurikulum 2013 dikembangkan berdasarkan faktor tantangan eksternal dan tantangan internal. Pada tantangan internal dikaitkan dengan tuntutan pendidikan yang mengacu pada standar nasional pendidikan, perkembangan penduduk Indonesia dilihat dari usia produktif. Faktor eksternal meliputi arus globalisasi dan juga perkembangan teknologi informasi serta perkembangan pendidikan tingkat Internasional [2].

Dengan kurikulum 2013 diharapkan setiap guru dituntut agar bisa menumbuhkan generasi - generasi yang beriman, produktif, kreatif, inovatif, afektif serta berkontribusi pada masyarakat. Untuk itu setiap guru harus terus belajar berdasarkan perkembangan teknologi. Dalam segi materi sudah dipastikan setiap guru mempunyai bekal yang cukup untuk mendidik siswa - siswanya. Akan tetapi untuk mengembangkan sistem dalam hal teknologi setiap guru mempunyai kemampuan yang berbeda - beda. Sehingga mereka harus tetap belajar agar proses di luar pengajaran berhasil [3].

Sebagai contoh pada Madrasah Ibtidaiyah MI Miftahul Hidayah yang bertempat di Kelurahan Pongangan Gunungpati Semarang. Dalam menghadapi kurikulum 2013, para guru merasa kesulitan dalam mengolah nilai raport. Pada pengolahan nilai raport, setiap sekolah sudah diberi sistem dari dinas pendidikan. Namun informasi dari yang didapat dari guru di MI Miftahul Hidayah, mereka sangat sulit menggunakan sistem tersebut. Mereka berharap ada sistem lain yang lebih mudah.

Berdasarkan uraian di atas, maka pada perlu adanya pendampingan untuk pengolahan nilai raport yang sesuai dengan kurikulum 2013. Pengolahan nilai raport yang dipilih adalah Microsoft Excel. Dengan Microsoft excel diharapkan bisa membantu guru - guru MI Mftahul Hidayah dalam pengolahan nilai raaport kurikulum 2013 [1].

\section{METODE PENELITIAN}

Pelaksanaan Pendampingan yang dilakukan di MI Miftahul Hidayah Pongangan Gunungpati Semarang diikuti oleh semua guru baik guru kelas maupun guru bidang studi khusus. Lokasi yang digunakan adalah ruang kelas 1A MI Miftahul Hidayah Pongangan Gunungpati Semarang. Pada kegiatan pendampingan ini dilakukan melalui beberapa tahapan yaitu : 1)Mengunjungi sekolah untuk bertemu Kepala Sekolah tentang masalah apa yang dihadapi oleh para guru dan mengajukan surat permohonan untuk menjadi mitra. 2)Menentukan waktu dan tempat pelaksanaan pendampingan. 3)Menyiapkan materi yang akan diberikan. 4)Permintaan pihak sekolah agar ditambah dengan materi tentang blok. 4)penyusunan kembali materi dan mengatur teknik pelaksanaan agar bisa tercapai target dari pendampingan ini. 5)Melakukan persiapan yang bersifat fisik antara lain : kesiapan laptop karena tidak semua guru mempunyai laptop, backdrop, perangkat dokumentasi, konsumsi, daftar hadir. 6)menyiapkan mahasiswa untuk menjadi asisten pada pelaksanaan pendampingan. 7)pengumpulan dokumentasi untuk digunakan penyusunan laporan pertanggungjawaban.

Dalam pelaksanaan pendampingan ini dilakukan tiga kegiatan, yaitu pemberian materi excel, pemberian materi tambahan blog dan tugas penyelesaian raport kurikulum 2013. Kegiatan tersebut bisa digambarkan sebagai berikut :

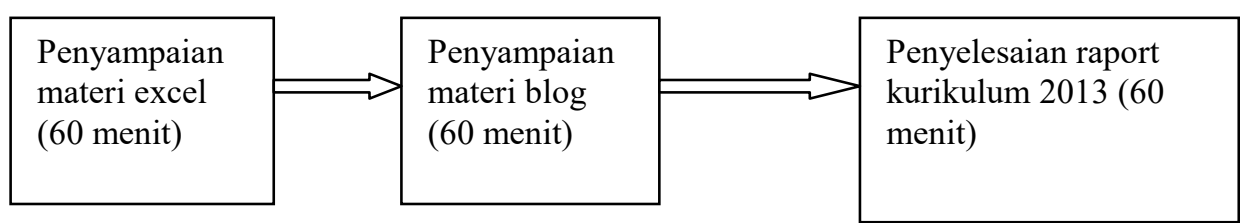

Gambar 1: Pelaksanaan Pendampingan Langsung

Pendampingan ini juga dibantu oleh dua mahasiswa TI Udinus sebagai asisten agar pendampingan lebih maksimal. 


\section{HASIL DAN PEMBAHASAN}

Pelaksanaan pendampingan diawali dengan pemberian materi excel. Materi excel yang diberikan adalah pengolahan nilai dengan operasi V-lookup. Dengan materi V-lookup maka guru akan bisa mengambil data dari sheet yang lain. Penerapan materi ini juga bisa digunakan untuk perankingan dan kriteria nilai siswa.

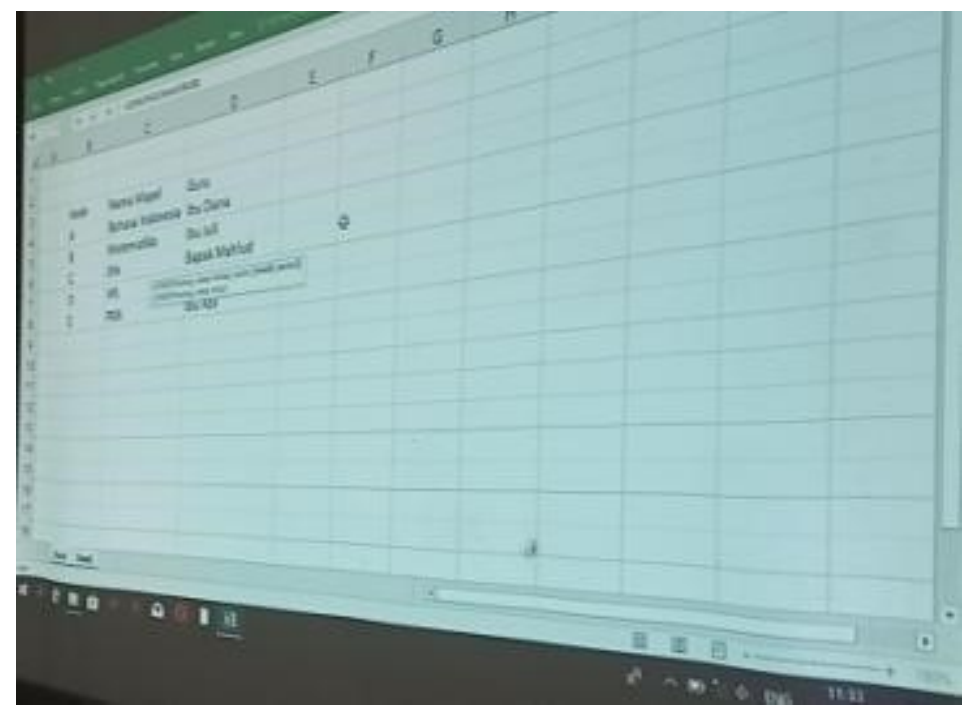

Gambar 1 : Materi awal excel

Selanjutnya setiap guru membuka sistem dapodik yang sudah dipelajari sebelum pelaksanaan pengabdian masyarakat di MI Miftahul Hidayah Gunungpati Semarang. Bentuk dari pembelajaran sebeliumnya yaitu dengan mendatangi mitra pada hari sabtu oleh pelaksana pengabdi. Bentuk dari sistem dapodik tersebut adalah sebagai berikut :

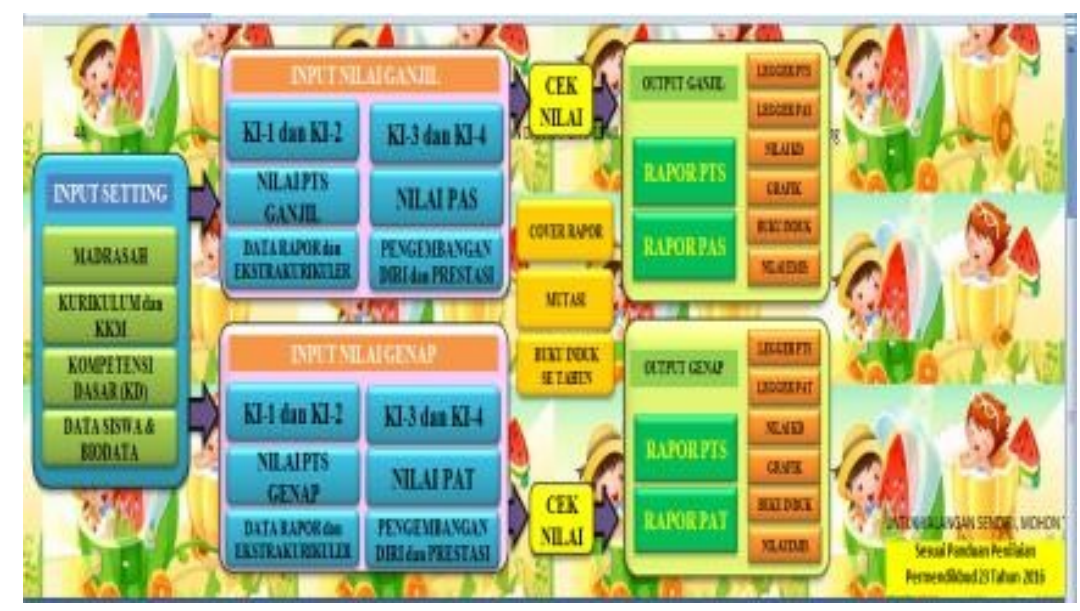

Gambar 2 : Sistem raport MI kurikulum 2013

Pelatihan dimulai langsung dengan pengisian nilai siswa karena untuk pengisian data telah diisi sebelum pelatihan berlangsung. 
ABDIMASKU, Vol. 2, No. 2, Juli 2019 : 73-78

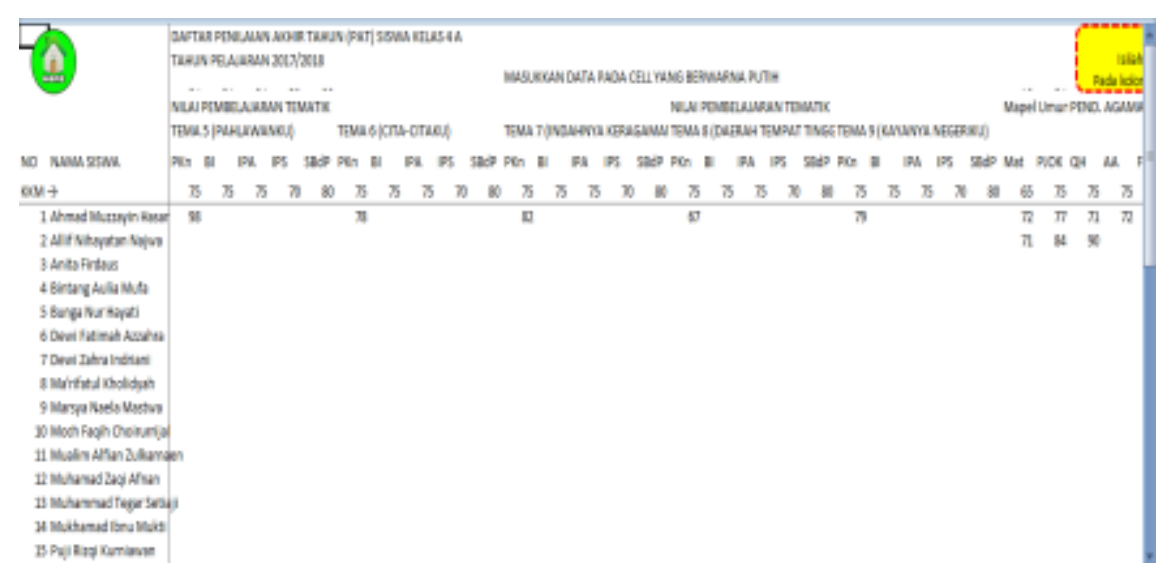

Gambar 3 : Pengisian nilai raport

Setelah selesai pengisian nilai, berikutnya pengecekan nilai yang telah diinputkan sebagai berikut :

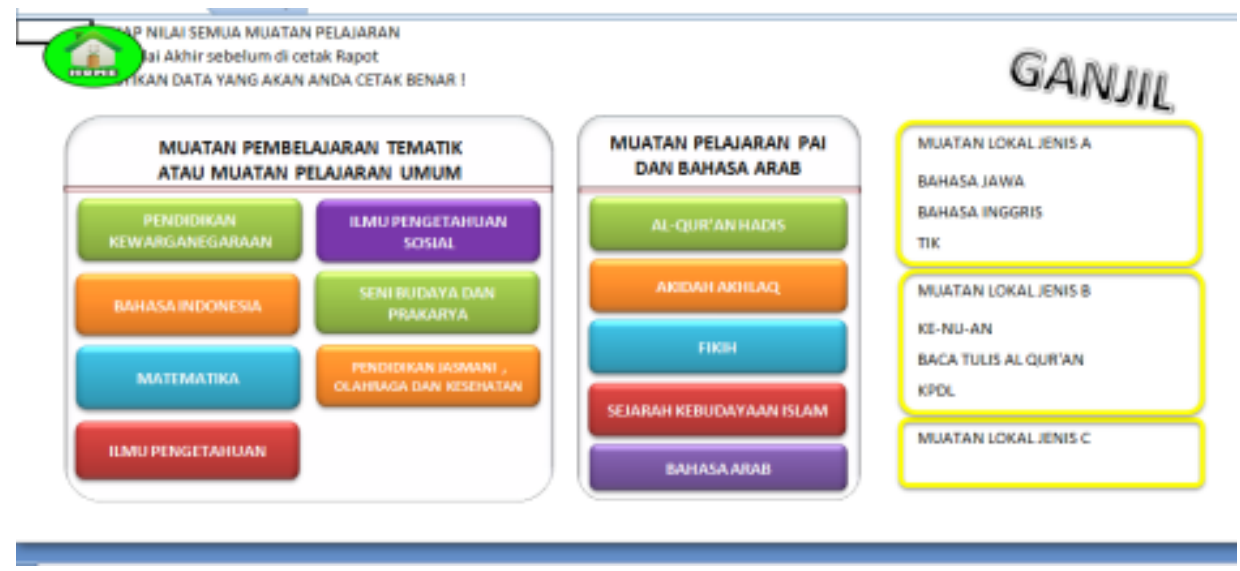

Gambar 4 : Pengecekan hasil input nilai

Setelah semua dicek maka akan dihasilkan raport seperti terlihat pada gambar 5 berikut ini : 


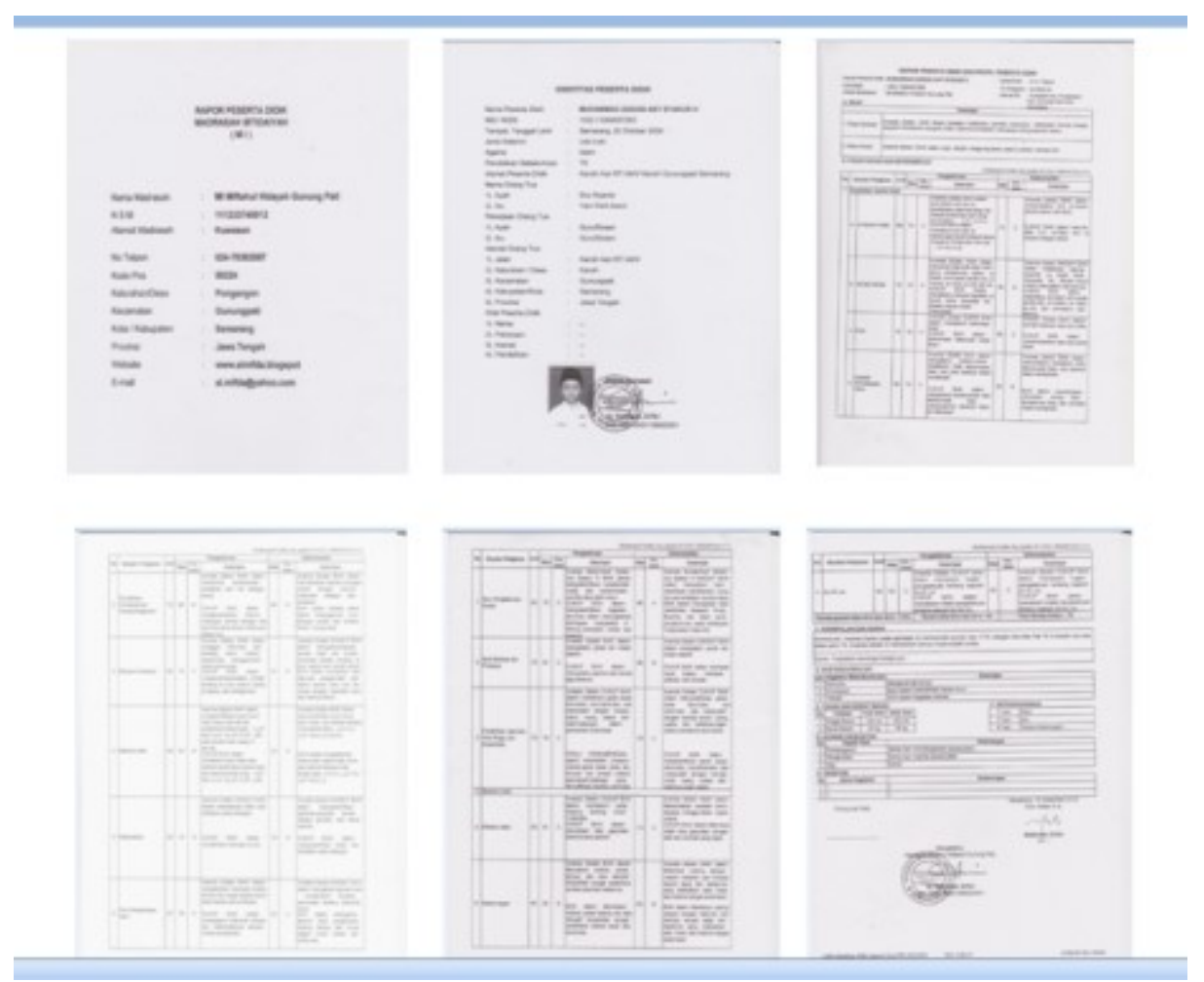

Gambar 5 : Hasil raport kurikulum 2013

Terlaksananya pengabdian ini berkat kerja sama antara Pengabdi dari Udinus dan pihak mitra MI Miftahul Hidayah Gunungpati Semarang seperti pada gambar berikut :
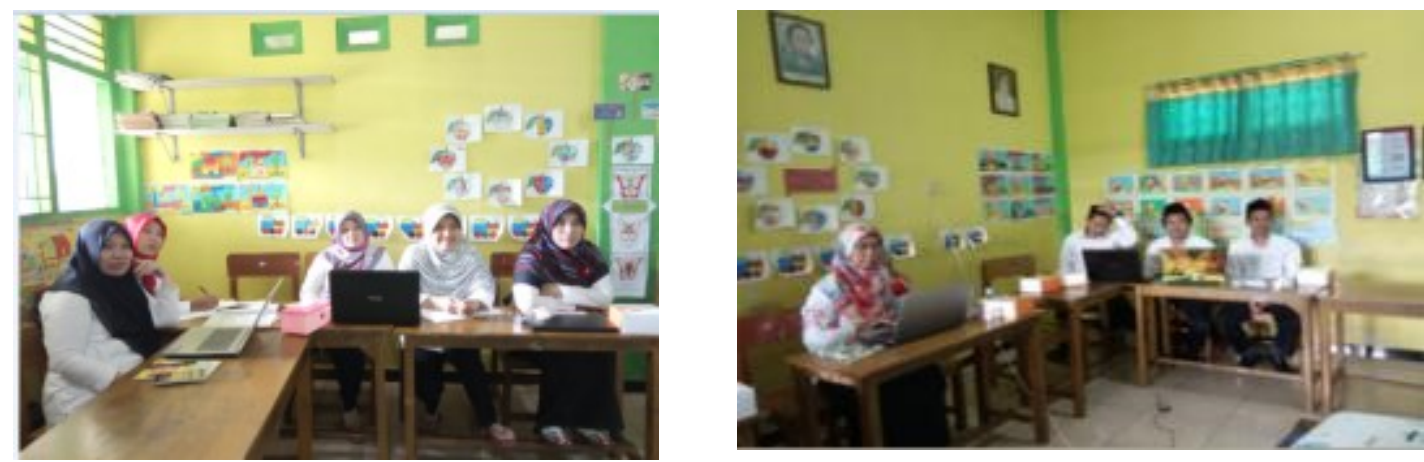

Gambar 6 : Peserta Pengabdian masyarakat
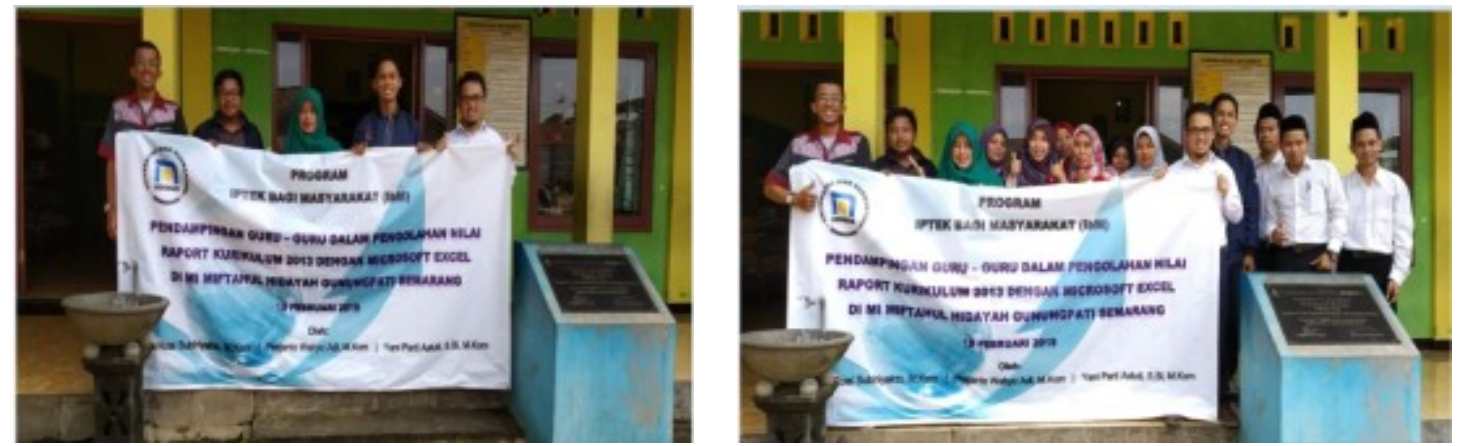

Gambar 7 : Pengabdi, assisten dan peserta pengabdian masyarakat 


\section{KESIMPULAN}

Dalam pengabdian masyarakat dengan mitra MI Miftahul Hidayah Gunungpati Semarang tentang pembuatan raport kurikulum 2013 telah memberikan hasil dan kesimpulan sebagai berikut :

1. Guru - guru bisa mengolah nilai dengan menggunakan Microsoft excel

2. Guru - guru bisa menyelesaikan pengisian raport kurikulum 2013 sesuai himbauan dinas pendidikan dengan sistem dapodik

\section{SARAN}

Setelah setiap guru mendapatkan materi tentang pengisian raport kurikulum 2013, maka diharapkan setiap guru bisa mengolah nilai dulu di excel sebelum diinputkan ke sistem. Hal ini akan membuat ketelitian terjaga.

\section{UCAPAN TERIMA KASIH}

Pengabdian masyarakat ini terlaksana berkat bantuan dana dari LPPM Udinus Semarang. Untuk itu dalam tulisan ini kami mengucapkan terima kasih kepada LPPM Udinus Semarang, Team Pengabdi, Semua pihak MI Miftahul Hidayah Gunungpati, Asisten mahasiswa TI Udinus Semarang

\section{DAFTAR PUSTAKA}

Undang - Undang No. 20, 2003, Sistem Pendidikan Nasional

Peraturan Menteri Pendidikan dan Kebudayaan Nomor 67, 2013

Maryono, atmosfer sekolah dasar dan implikasinya bagi pendidikan guru sekolah dasar, Tahun 2017, Jurnal Ilmiah Universitas Batanghari Jambi Vol.17 No.1

Newmark, P. ( 1991). About translation. Clevedon [England]: Multilingual Matters. England.

Wahono, R. S. (2008). Memanfaatkan Internet untuk Personal Branding . Retrieved from Ilmu Komputer.org. 